\title{
Somatic Symptom Disorders and Utilization of Health Services among Palestinian Primary Health Care Attendees: A Cross-sectional Study
}

\section{Zaher Nazzal ( $\nabla$ znazzal@najah.edu )}

An-Najah National University

\section{Beesan Maraqa}

An-Najah National University

Marah Abu Zant

An-Najah National University

Layali Qaddoumi

An-Najah National University

\section{Rana Abdallah}

An-Najah National University

\section{Research Article}

Keywords: Somatic symptom disorder, Primary Care clients, Risk factor, Palestine

Posted Date: December 14th, 2020

DOI: https://doi.org/10.21203/rs.3.rs-123167/v1

License: (c) (1) This work is licensed under a Creative Commons Attribution 4.0 International License. Read Full License 


\section{Abstract}

Background: Many primary health care (PHC) clients come in with medically unexplained complaints, leading to frequent consultations and high usage of services and healthcare costs. This study aimed to determine the prevalence of somatic symptom disorder (SSD) among PHC attendees and explore its relation to other mental conditions and risk factors.

Methods: A cross-sectional design was used to interview 400 attendees. Men and women aged over 18 years old without a psychiatric diagnosis were invited to participate. The Somatization scale of the FourDimensional Symptom Questionnaire was used to assess somatic symptom disorders. It is a valid tool to be used in a PHC setting. We used the Chi-square test and multivariable logistic regression to explore determinant variables.

Results: Prevalence of SSD was $32.5 \%$ (95\% Cl= 27.9\%-37.1\%). The most common symptoms were painful muscles $(61.5 \%)$ followed by back pain (52.3\%). Female gender [adjusted $\mathrm{OR}=2.2(95 \% \mathrm{Cl}=1.3-$ 4)], chronic diseases [adjusted $\mathrm{OR}=2(95 \% \mathrm{Cl}=1.1-3.6)$ ], depression [adjusted $\mathrm{OR}=3.2(95 \% \mathrm{Cl}=2.0-5.3)$ ], and anxiety [adjusted $\mathrm{OR}=3.0(95 \% \mathrm{Cl}=1.6-5.5)$ ] were all associated with SSD. In addition, frequent primary health care attendance was found to be associated with SSD [adjusted OR $=2.2(95 \% \mathrm{Cl}=1.3-$ 4.0)]

Conclusions: SSD significantly higher among females, patients with chronic diseases, clients with anxiety and depressive disorders, and patients with frequent doctors' visits. Painful muscles and back pain are the most common symptom presented by patients, and this could be used initially by PHC physicians as a signal to consider for screening.

\section{Introduction}

Somatization is the expression of psychological or emotional distress through physical symptoms that are otherwise unexplained. It has been argued that it is so common in primary health care (PHC) as to be considered the norm, not the exception . ${ }^{1}$ Somatic symptom disorder (SSD), the new term used for somatization in the Diagnostic Statistical Manual 5th edition (DSM-V), requires significant attention to physical symptoms being experienced by a person such as pain, weakness, or shortness of breath that contributes to discomfort and/or functioning problems. The person has physical symptoms related to repetitive thinking, feelings, and behaviors. Physical symptoms may or may not be associated with a particular medical condition, but people experience symptoms and feel ill. ${ }^{2}$

SSD has been considered as a significant problem, particularly in $\mathrm{PHC}{ }^{3}$ Patients with numerous recurring physical symptoms that do not appear to have any apparent biological basis are frequent among PHC clients. ${ }^{4}$ The prevalence of SSD is inconsistent and varies significantly between different countries and communities, depending on the population of the underlying study and the diagnostic criteria used in single studies. ${ }^{5-7}$ The results of a regional Iranian study showed a high prevalence of somatic symptoms 
of varying severity. Age, marital status, education, socio-economic status, anxiety, and depression were reported as significant risk factors. ${ }^{6}$ On the other hand, SSD was associated with female gender and low educational level among Kuwaiti PHC attendees. ${ }^{5}$

The link between SSD and other mental health conditions, such as depression and anxiety, has been extensively studied. A large population-based study showed a strong relationship between depressive and anxiety disorders and somatic symptoms. ${ }^{8} \mathrm{~A}$ further general population study showed that somatic symptoms and anxiety are often overlapping and that they are associated with the increased use of healthcare services. ${ }^{9}$ Somatic symptoms were common among the younger population, and an association with depression was reported. The combination of somatic, anxiety and depression syndrome described as the 'somatization-anxiety-depression (SAD) triad has been reported to be a significant disease burden,, 10 as well as being associated with greater severity and duration of depression and psychiatric co-morbidity and a strong correlation to suicidal plans and attempts. ${ }^{11}$

SSD is mainly present in PHC settings; it is linked to patients' frequent visits to clinics, contributing to recurrent use of medical services and frustration for patient and doctor alike. ${ }^{3}$ The attendance level of such patients was calculated to be $60 \%$ higher than that of non-diagnosed patients. ${ }^{7}$ It increases the use of existing services and the burden on doctors and health staff, particularly in low and medium incomes countries like Palestine, which suffers from occupation and scarcity of resources.

In Palestine, a significant number of patients with unexplained medical symptoms visit PHC clinics daily, despite clinical training improvements for primary care physicians aimed at early detection of mental health conditions. Most patients go unnoticed in the context of a lack of a screening method to be applied at the primary care level for somatic symptom disorder. To the best of our understanding, the SSD studies in Palestine are minimal, and diagnostic risk factors have not been identified. Given the seriousness of the problem and the associated diagnosis of other mental disorders, such as depression and anxiety, we conducted this study to determine the prevalence of SSD, factors connected to it, and the relation between this disorder and anxiety and depression.

\section{Materials And Methods}

\section{Study design and population}

A cross-sectional study was conducted in large PHC centers in North Palestine. A convenient sample of clients attending PHC centers was collected. Participants were recruited from clients who visited PHC clinics in Nablus, the second largest district of West-Bank. Visits to the clinic were for general medical problems and/or regular wellness visits, and the interviews took place between July and Jan 2020. The majority of Palestinian communities living in the West Bank are covered by national health insurance, including all PHC services. Legibility criteria for inclusion in the study are any person -male or femaleabove 18 years of old with no previous mental health illness diagnosis. Participants who failed to finish the surveys used in this analysis were disqualified or had too many missing values. 
The sample size was based on the assumption that in Palestine, the prevalence of somatization was similar to levels in some of the eastern Mediterranean countries, which ranged from 11-35\%. ${ }^{5,12}$ Given the unique Palestinian situation in the presence of occupation as an additional psychological factor, we assumed that the SSD prevalence would be $35 \%$, with a fault interval of $95 \%$ at the significance level of $5 \%$, a minimum sample size of 364 would be necessary for the study objectives to be achieved.

The study was approved by the An-Najah National University institutional review board (IRB) and the Palestinian Ministry of Health. After the purpose and objectives of the research were presented, PHC clients were approached and encouraged to participate voluntarily in the study.

\section{Measures}

The 16-point Somatization Scale of the four-Dimensional Symptom Questionnaire (4DSQ) has been used to test the SSD since it is a reliable tool used for assessing somatization in $\mathrm{PHC} .^{13}$ The questionnaire is designed to evaluate common somatic symptoms among PHC patients and determine whether any additional diagnoses are needed. It is designed on the basis that "Average" people experiencing one or even a few scientifically unexplained signs, for example, being dizzy with stomach pain, could be a normal finding under stressful circumstances. Yet, having other unexplained encounters originating from various organ systems (i.e., stomach pain and palpitation and muscle aches) may indicate SSD. ${ }^{14}$ The instrument is coded on a continuous scale varying between 0 and 32. Coding was used as a categorical group for the 4DSQ-somatisation questionnaire: $0-10$ is considered low or absent, moderately elevated if score $10-20$ and high if the score was more than $20 .{ }^{13}$

The other parts of the 4DSQ assessed for anxiety (12 items) and for depression (6 items). For each symptom in each scale, 0 points are recorded if a symptom is absent, 1 point if a symptom is 'sometimes' present, and 2 points if a symptom is 'regularly' or more often present. Therefore, the total 4DSQ score for anxiety ranges from 0 to 24 , with scores of $0-3,4-8$, and 9-24 representing 'low,' 'moderately high' and 'very high' risk of anxiety level. For depression, the total 4DSQ score ranges from 0 to 12 , with scores of $0-2,3-5$, and 6-12 representing 'low', 'moderately high' and 'very high' risk of depression levels, respectively. ${ }^{13}$ The Arabic version of the questionnaire was finalized after translation and back translation of the original one. Then, it was reviewed by experts in the field before being piloted on a group of PHC clients to ensure its validity and reliability.

The frequency of doctor visits was measured via a direct question asking participants about their number of visits per month to PHC doctors. There is no standard definition for frequent doctor visits, varying from 5 to 20 visits per year. ${ }^{15}$ In this study, doctor visits were grouped as one visit or less per month vs. more than one visit per month.

Based on a literature review, the following variables were independently identified as potential risk factors for SSDs: gender, age, marital status, levels of education, chronic diseases, and symptoms of depression and anxiety. Age was split into two groups, with 50 years of age as a cutoff point. The marital status of participants divided into two groups: single vs. married, widowed, or divorced. The level of education was 
divided into two categories (an alphabet and school or university and higher). Chronic diseases were assessed using a yes/no question subjectively reported by participants.

\section{Data analysis}

The statistical package for social science (SPSS v. 21) software was used for data management. Descriptive statistics, including mean, SD, frequencies, and percentages, were used to describe data. SSD, depression, and anxiety were recorded as dichotomous variables like the presence of SSD (a score $<11=$ $0, \geq 10=1$ ) or the absence of a depression (a score $<3=0, \geq 3=1$ ), or anxiety (a score $<4=0, \geq 4=1$ ). Each of them was then used as a dependent variable and assessed with background variables. Chisquare test, with odds ratios (OR) and their respective $95 \%$ confidence intervals $(\mathrm{Cl})$ was used to determine associations for categorical variables. A multivariable logistic regression model was used to adjust for confounders and predict the associations between background variables and anxiety or depression with SSD. The significance level was set at a $p$-value of $<0.05$. The performance to indicate SSD was examined using the receiver operating characteristic (ROC) curve. The curve represented a plot of sensitivity versus 1 - specificity. The area under the curve (AUC) was derived from the ROC curve.

\section{Results}

Four hundred PHC clients agreed to participate in the study and were interviewed. Almost three fourths $(71.8 \%)$ were female, and more than half $(52.3 \%)$ were over 50 years of age. The majority were married (77.5\%), unemployed (66.2\%), and had an average monthly income of 300-600JD (52.7\%). Almost two thirds (64\%) reported having a chronic disease such as hypertension, diabetes, or coronary artery disease, and $23.3 \%$ of the participants have more than one chronic disease at the same time. For doctor visits, $22.6 \%$ saw a doctor more than once a month. Table 1 presents the background characteristics of the sample. Almost one third $(32.5 \%)[95 \% \mathrm{Cl}=27.9 \%-37.1 \%]$ of the participants found to have SSD, $41.8 \%$ $[95 \% \mathrm{Cl}=36.9 \%-46.8 \%]$ have depressive disorders, and $38.5 \%[95 \% \mathrm{Cl}=33.7 \%-43.5 \%]$ have depressive disorders (Table 1).

Significantly higher proportions of SSD were found among female clients [( $37.9 \%$ vs $18.6 \%), p$-value< 0.001 ], clients with single marital status [( $47.7 \%$ vs $28.1 \%), p$-value $<0.001]$, clients with school or illiterate educational level [( $36.2 \%$ vs $24.4 \%), p$-value $=0.018]$, clients with very low monthly income [( $43.1 \%$ vs $30.3 \%$ and $27.1 \%) p$-value $=0.04]$, clients with one or more than one chronic diseases $[(37.8 \%$ and $35.1 \%$ vs $24.6 \%), p$-value $=0.028$, those with high depressive scores [( $51.5 \%$ vs $18.9 \%), p$-value $<0.001]$, and those with high anxiety scores [(66.6\% vs $26.0 \%), p$-value $<0.001]$. SSD were significantly higher among frequent users of PHC services [(50.0\% vs $27.2 \%), p$-value $<0.001]$ (Table 1$)$. 
Table 1

Distribution of socio-demographic characteristics of the total sample and clients with mental disorders

\begin{tabular}{|c|c|c|c|c|}
\hline Variables & $\begin{array}{l}\text { Total } \\
{[n=400(100 \%)]}\end{array}$ & $\begin{array}{l}\text { Somatic symptom } \\
\text { disorder } \\
\text { [n=130 (32.5\%)] }\end{array}$ & $\begin{array}{l}\text { Depression } \\
{[n=167} \\
(41.8 \%)]\end{array}$ & $\begin{array}{l}\text { Anxiety } \\
{[n=154} \\
(38.5 \%)]\end{array}$ \\
\hline \multicolumn{5}{|l|}{ Age } \\
\hline$<50$ Years & 191(47.8\%) & $58(30.4 \%)$ & 68 (35.6\%) & 88 (46.1\%) \\
\hline$\geq 50$ Years & 209 (52.3\%) & 72(34.4\%) & 99 (47.4\%) & 66 (31.6\%) \\
\hline P-value & & 0.40 & 0.017 & 0.003 \\
\hline \multicolumn{5}{|l|}{ Gender } \\
\hline Male & $113(28.2)$ & 21(18.6\%) & 35 (31.0\%) & 14 (12.4\%) \\
\hline Female & 287(71.8) & 109(37.9\%) & $132(46.0 \%)$ & $140(48.8 \%)$ \\
\hline P-value & & $<0.001$ & 0.006 & $<0.001$ \\
\hline \multicolumn{5}{|c|}{ Marital Status } \\
\hline Married & $310(77.5 \%)$ & $87(28.1 \%)$ & $112(36.1 \%)$ & $111(35.8 \%)$ \\
\hline Singlet & $90(22.5 \%)$ & 43(47.7\%) & 55 (61.1\%) & 43 (47.8\%) \\
\hline P-value & & $<0.001$ & $<0.001$ & 0.40 \\
\hline \multicolumn{5}{|l|}{$\begin{array}{l}\text { Educational } \\
\text { Level }\end{array}$} \\
\hline School & $268(67.2 \%)$ & $97(36.2 \%)$ & $131(48.9 \%)$ & 34 (26.0\% \\
\hline University & $131(32.8 \%)$ & $32(24.4 \%)$ & 35 (26.7\%) & 119 (44.4\%) \\
\hline P-value & & 0.018 & $<0.001$ & $<0.001$ \\
\hline \multicolumn{5}{|l|}{ Employed } \\
\hline No & 265 (66.3\%) & $94(35.5 \%)$ & 118 (44.5\%) & $118(44.5 \%)$ \\
\hline Yes & 135 (33.8\%) & $36(26.7 \%)$ & 49 (36.3\%) & $135(26.7 \%)$ \\
\hline P-value & & 0.075 & 0.114 & 0.001 \\
\hline \multicolumn{5}{|l|}{$\begin{array}{l}\text { Monthly } \\
\text { Income }\end{array}$} \\
\hline$<300 J D$ & $\begin{array}{l}96(24.0 \%) \\
211(527 \%)\end{array}$ & $40(43.1 \%)$ & $56(60.2 \%)$ & 21 (21.9\%) \\
\hline 300-600JD & $93(23.3 \%)$ & 64(30.3\%) & 82 (38.9\%) & 89 (42.2\%) \\
\hline > 600JD & & $26(27.1 \%)$ & 29 (30.2\%) & $44(47.3 \%)$ \\
\hline
\end{tabular}




\begin{tabular}{|c|c|c|c|c|}
\hline Variables & $\begin{array}{l}\text { Total } \\
{[n=400(100 \%)]}\end{array}$ & $\begin{array}{l}\text { Somatic symptom } \\
\text { disorder } \\
\text { [n }=130(32.5 \%)]\end{array}$ & $\begin{array}{l}\text { Depression } \\
{[n=167} \\
(41.8 \%)]\end{array}$ & $\begin{array}{l}\text { Anxiety } \\
{[n=154} \\
(38.5 \%)]\end{array}$ \\
\hline P-value & & 0.04 & $<0.001$ & $<0.001$ \\
\hline \multicolumn{5}{|l|}{$\begin{array}{l}\text { Chronic } \\
\text { Disease }\end{array}$} \\
\hline None & $144(36 \%)$ & 35 (24.6\%) & 50 (35.2\%) & $63(44.4 \%)$ \\
\hline One & $163(40.7 \%)$ & 62 (37.8\%) & 73 (44.5\%) & 59 (36.0\%) \\
\hline More than one & $93(23.3 \%)$ & 33 (35.1\%) & 44 (46.8\%) & 32 (34.0\%) \\
\hline P-value & & 0.028 & 0.123 & 0.653 \\
\hline \multicolumn{5}{|l|}{ Doctor visit } \\
\hline \multirow{2}{*}{$\begin{array}{l}\leq \text { Once a } \\
\text { month } \\
>\text { Once a } \\
\text { month }\end{array}$} & 309 (77.4\%) & $84(27.2 \%)$ & $121(39.2 \%)$ & $108(35.0 \%)$ \\
\hline & $90(22.6 \%)$ & $45(50.0 \%)$ & $46(51.1 \%)$ & $45(50.0 \%)$ \\
\hline P-value & & $<0.001$ & 0.052 & 0.010 \\
\hline \multicolumn{5}{|l|}{ Doctor visit } \\
\hline$<1$ a month & 71(17.8) & 13(18.3) & 20 (28.2\%) & 29 (40.0\%) \\
\hline 1 a month & 238(59.5) & $71(29.8)$ & 101 (42.4\%) & 79 (33.2\%) \\
\hline 2 a month & $56(14.0)$ & $24(42.8)$ & 26 (46.4\%) & $27(48.2 \%$ \\
\hline 3 a month & $21(5.2)$ & $12(57.1)$ & $12(57.1 \%)$ & $11(52.4 \%)$ \\
\hline$\geq 4$ a month & $14(3.5)$ & 10(71.4) & 8 (57.1\%) & $8(57.1 \%)$ \\
\hline P-value & & $<0.001$ & 0.053 & 0.001 \\
\hline \multicolumn{5}{|l|}{ Depression } \\
\hline Low & $233(59.2 \%)$ & $44(18.9 \%)$ & -- & -- \\
\hline High & $167(41.8 \%)$ & $86(51.5 \%)$ & & \\
\hline$p$-value & & $<0.001$ & & \\
\hline \multicolumn{5}{|l|}{ Anxiety } \\
\hline Low & $264(61.5 \%))$ & $87(21.2 \%)$ & - & - \\
\hline High & 154 (38.5\%) & 77 (50.0\%) & & \\
\hline$p$-value & & $<0.001$ & & \\
\hline
\end{tabular}




\begin{tabular}{|lllll|}
\hline Variables & Total & $\begin{array}{l}\text { Somatic symptom } \\
\text { disorder }\end{array}$ & $\begin{array}{l}\text { Depression } \\
{[n=400(100 \%)]}\end{array}$ & $\begin{array}{l}\text { Anxiety } \\
{[n=167}\end{array}$ \\
& {$[n=130(32.5 \%)]$} & $(41.8 \%)]$ & $(38.5 \%)]$ \\
\hline
\end{tabular}

Multivariable logistic regression was conducted to control for confounders. SSD was associated with: female gender $[p$-value $=0.004$ adjusted $\mathrm{OR}=2.2(95 \% \mathrm{Cl}=1.3-4.0)]$, clients with chronic diseases $[p$ value $=0.025$ adjusted $\mathrm{OR}=1.9(95 \% \mathrm{Cl}=1.1-3.3)]$, clients with high depression scores $[p$-value $<0.001$ adjusted $\mathrm{OR}=3.2(95 \% \mathrm{Cl}=2.0-5.3)]$, and clients with high anxiety scores [ $p$-value $=0.032$ adjusted $\mathrm{OR}=$ $3.0(95 \% \mathrm{Cl}=1.6-5.5)]$. Additionally, patients with high SSD were found to have significantly higher frequency of doctors visit per month $[p$-value $=0.005$ adjusted $\mathrm{OR}=2.2(95 \% \mathrm{Cl}=1.3-4.0)]($ Table 2$)$ 
Table 2

Logistic regression analysis of predictors of high somatic symptom disorder among PHC clients

\begin{tabular}{|c|c|c|c|c|}
\hline Variables & S.E & P Value* & Adjusted OR & $95 \% \mathrm{Cl}$ \\
\hline \multicolumn{5}{|l|}{ Gender } \\
\hline Malet & 0.324 & 0.015 & 2.2 & $1.3-4.0$ \\
\hline \multicolumn{5}{|l|}{ Female } \\
\hline \multicolumn{5}{|l|}{ Marital Status } \\
\hline Marriedt & 0.285 & 0.26 & 1.4 & $0.7-2.6$ \\
\hline \multicolumn{5}{|l|}{ Unmarried } \\
\hline \multicolumn{5}{|l|}{ Educational Level } \\
\hline Schoolt & 0.302 & 0.171 & 1.2 & $0.70-2.1$ \\
\hline \multicolumn{5}{|l|}{ University } \\
\hline \multicolumn{5}{|l|}{ Salary } \\
\hline$<300 J D$ & 0.33 & 0.69 & 0.88 & $0.46-1.7$ \\
\hline 300-600JD & 0.39 & 0.84 & 0.93 & $0.42-2.02$ \\
\hline \multicolumn{5}{|l|}{ > 600JD† } \\
\hline \multicolumn{5}{|l|}{ Chronic Disease } \\
\hline Nonet & 0.27 & 0.027 & 2.0 & $1.1-3.6$ \\
\hline One & & 0.226 & 1.5 & $0.81-3.1$ \\
\hline \multicolumn{5}{|l|}{ More than one } \\
\hline \multicolumn{5}{|l|}{ Doctor visits } \\
\hline$\leq$ Once a month $\uparrow$ & 0.27 & 0.005 & 2.2 & $1.3-4.0$ \\
\hline > Once a month & & & & \\
\hline \multicolumn{5}{|l|}{ Depression } \\
\hline Lowt & 0.256 & $<0.001$ & 3.2 & $2.0-5.3$ \\
\hline \multicolumn{5}{|l|}{ High } \\
\hline \multicolumn{5}{|l|}{ Anxiety } \\
\hline Lowt & 0.323 & 0.031 & 3.0 & $1.6-5.5$ \\
\hline High & & & & \\
\hline
\end{tabular}




\begin{tabular}{|c|c|c|c|c|}
\hline Variables & S.E & P Value* & Adjusted OR & $95 \% \mathrm{Cl}$ \\
\hline
\end{tabular}

Common physical complaints were evaluated among participants and highly prevalent among clients with moderate to high SSD scores. The most common complaints were painful muscles (61.5\%) and back pain (52.3\%), followed by tingling in the fingers (43.8\%), neck pain (40.8\%), and excessive sweating (39.2\%) (Table 3).

Clients with moderate to high SSD scores are more likely to suffer from physical complaints than those with low scores. They are eight times more likely to have painful muscles ( $p$-value $<0.001), 6.9$ times more likely to have back pain ( $p$-value $<0.001), 6.5$ times more likely to have tingling figures ( $p$-value < $0.001), 8.2$ times more likely to have neck pain ( $p$-value $<0.001$ ), and 5.2 times more likely to have excessive sweating ( $p$-value $<0.001$ ). Table 3 presents in detail the frequency of physical complaints and compare between the two groups. 
Table 3

Distribution of last week's physical complaints among the participants and its relation with high somatic symptom disorder score

\begin{tabular}{|c|c|c|c|c|c|}
\hline \multirow[t]{2}{*}{ Complain } & \multirow[t]{2}{*}{ Total } & \multicolumn{2}{|c|}{$\begin{array}{l}\text { Somatic symptom } \\
\text { disorder }\end{array}$} & \multirow[t]{2}{*}{$\begin{array}{l}\text { P- } \\
\text { value* }\end{array}$} & \multirow[t]{2}{*}{ OR $(95 \% \mathrm{Cl})$} \\
\hline & & Low & High & & \\
\hline Painful muscles & $\begin{array}{l}125 \\
(31.3 \%)\end{array}$ & $\begin{array}{l}45 \\
(16.7 \%\end{array}$ & $\begin{array}{l}80 \\
(61.5 \%)\end{array}$ & $<.001$ & $8(4.9-12.8$ \\
\hline Back pain & $\begin{array}{l}105 \\
(26.3 \%)\end{array}$ & $\begin{array}{l}37 \\
(13.7 \%)\end{array}$ & $\begin{array}{l}68 \\
(52.3 \%)\end{array}$ & $<.001$ & $\begin{array}{l}6.9(4.3- \\
11.3^{-}\end{array}$ \\
\hline Tingling fingers & $\begin{array}{l}86 \\
(21.5 \%)\end{array}$ & $\begin{array}{l}29 \\
(10.7 \%)\end{array}$ & $\begin{array}{l}57 \\
(43.8 \%)\end{array}$ & $\dot{0} 001$ & $\begin{array}{l}6.5(3.9- \\
10.9)\end{array}$ \\
\hline Neck pain & $\begin{array}{l}74 \\
(18.5 \%)\end{array}$ & $21(7.8 \%)$ & $\begin{array}{l}53 \\
(40.8 \%)\end{array}$ & $<.001$ & $\begin{array}{l}8.2(4.6- \\
14.4)\end{array}$ \\
\hline Excessive sweating & $\begin{array}{l}81 \\
(20.3 \%)\end{array}$ & $\begin{array}{l}30 \\
(11.1 \%)\end{array}$ & $\begin{array}{l}51 \\
(39.2 \%)\end{array}$ & $<.001$ & $\begin{array}{l}5.2(3.1- \\
8.7)\end{array}$ \\
\hline Bloated feeling in the abdomen & $61(15.3)$ & $12(4.4 \%)$ & $\begin{array}{l}49 \\
(37.7 \%)\end{array}$ & $<.001$ & $\begin{array}{l}13(6.6- \\
25.6)\end{array}$ \\
\hline Headache & $\begin{array}{l}60 \\
(15.0 \%)\end{array}$ & $15(5.6 \%)$ & $\begin{array}{l}45 \\
(34.6 \%)\end{array}$ & $<.001$ & $9(4.8-16.9)$ \\
\hline Dizziness or feeling light-headed & $56(14 \%)$ & $17(6.3 \%)$ & $\begin{array}{l}39 \\
(30.0 \%)\end{array}$ & $<0.001$ & $\begin{array}{l}6.5(3.5- \\
11.9)\end{array}$ \\
\hline Shortness of breath & $37(9.3 \%)$ & $5(1.9 \%)$ & $\begin{array}{l}32 \\
(24.6 \%)\end{array}$ & $<.001$ & $17(66-457)$ \\
\hline $\begin{array}{l}\text { Blurred vision or spots in front of } \\
\text { your eyes }\end{array}$ & $39(9.8 \%)$ & $11(4.1 \%)$ & $\begin{array}{l}28 \\
(21.5 \%)\end{array}$ & $<0.001$ & $\begin{array}{l}6.5(3.1- \\
13.5)\end{array}$ \\
\hline Nausea or an upset stomach & $33(8.3 \%)$ & $6(2.2 \%)$ & $\begin{array}{l}27 \\
(20.8 \%)\end{array}$ & $<0.001$ & $\begin{array}{l}11.5(4.7- \\
28.8)\end{array}$ \\
\hline Abdominal pain or stomachache & $29(8.3 \%)$ & $3(1.1 \%)$ & $26(2.0 \%)$ & $<.001$ & $\begin{array}{l}22.3(6.6- \\
75.1)\end{array}$ \\
\hline Palpitations & $33(8.3 \%)$ & $8(3.0 \%)$ & $\begin{array}{l}25 \\
(19.2 \%)\end{array}$ & $<0.001$ & $\begin{array}{l}7.8(3.4- \\
17.8)\end{array}$ \\
\hline Chest pressure or a tight feeling & $25(6.3 \%)$ & $2(0.7 \%)$ & $\begin{array}{l}23 \\
(17.7 \%)\end{array}$ & $<.001$ & $\begin{array}{l}28(6.7- \\
124.3)\end{array}$ \\
\hline Chest pain & $12(3.5)$ & $3(1.1 \%)$ & $9(6.9 \%)$ & 0.001 & $\begin{array}{l}6.6(1.6- \\
24.9)\end{array}$ \\
\hline
\end{tabular}

The probability for each symptom to predict SSD was measured by ROC analysis of physical complaints. The ROC showed significant predictive power of painful muscles $(A U C=0.724)$, back pain $(A U C=0.693)$, 
tingling fingers $(A \cup C=0.666)$, neck pain $(A U C=0.665)$, and bloated feeling in the abdomen $(A U C=0.666)$ for high somatic symptom (SSD) score (Fig. 1).

\section{Discussion}

Somatic symptom disorders in primary care have not been extensively researched compared with other mental disorders. The few studies found didn't use standardized criteria for sensitive comparison and enhancing generalist care. ${ }^{4}$ However, the present study shows that SSD is prevalent in primary care patients in Palestine, 32.5 percent of whom have a moderate and high somatization score. This result is in the most upper range, comparable to other studies worldwide. A systemic review reported a prevalence range from 26.2-34.8\% of SSD diagnosable by either DSM criteria and/or ICD-10 criteria in the PHC setting. ${ }^{16}$ Additionally, it was the most prevalent mental health morbidity among Kuwaiti primary care attendees. ${ }^{17}$ Such statistics demonstrate that SSD presents a highly significant public health concern that is not trivial, especially in the Palestinian community with its unique conflict situation, as this will carry a higher burden on health care setting in terms of health care utilization and cost compared to other economically and politically stable countries. ${ }^{15}$

A significant result is obtained in this study is the association between SSD with doctor visits, which reflects health care utilization. A finding that is consistent with a highly significant $p$-value (0.005) even after controlling different confounders. Literature showed a consensus that underdiagnosed SSD would result in higher health care utilization, higher morbidity, and lower health-related quality of life. ${ }^{15,18,19}$ Patients with SSD appear to have frequent visits and contacts with their PHC physicians as they feel unhappy with their medical tests, resulting in increased use of medical resources. Patients who have mental disorders tend to be frequent visitors. ${ }^{20}$ This, in turn, will pressure the already overloaded PHC clinics in Palestine on the one hand and increasing health care costs in this low-income country on the other side. Furthermore, it is a big challenge for PHC physicians in dealing with uncertainty regarding the diagnosis in this highly-stressed clinical population with their usually somatically focused health concepts. A situation that will result in unnecessary medical treatments and referrals whereas short term psychotherapy could be the more convenient, cheaper and best choice. ${ }^{21}$

The association between SSD and the female gender is consistent with previous findings. Our results align with Alkhadhari and colleagues who reported a strong association between SSD and female gender among the Kuwaiti population ${ }^{5}$. This could be attributed to specific cultural norms related to the Arab world and the inherent differences between males and females concerning somatic and emotional perception. Gender imbalance in the rates of abuse and violence; gender disparities in the incidence of anxiety and depressive disorders; and gender inequality may also affect these findings. ${ }^{22}$

Mechanisms linking co-morbid mental and chronic diseases are complex and bi-directional. Chronic illness can affect mental health and lead to psychological disorders, and an individual may be subjected 
to chronic physical disease by a psychological disorder. Other mental and physical conditions share risk factors such as chronic social stress, inactivity, overweight, smoking, alcohol use, and endocrine disorders. ${ }^{23}$ Many studies examined the association between SSD and the presence of chronic disease. They revealed a strong association, increasing in strength, with an increasing number of chronic diseases diagnosed in a single person. ${ }^{17,24}$ For example, a large population-based study found a strong association between heart attacks and the history of major surgeries and SSD. ${ }^{25}$ SSD, on the other hand, was the most common co-morbid mental disorder associated with chronic disease and the one most implicated in poorer prognosis, increased use of health care, higher cost of health care, and more inadequate compliance with treatment. ${ }^{17,26,27}$

A statistically significant relationship between SSD and depressive disorder has been shown in several studies. ${ }^{6,28,29}$ The overlap between these disorders was also documented in various studies. ${ }^{5,12}$ As a result, screening for mental health problems in patients with unexplained symptoms could be recommended based on these results. However, this was not justified by a large longitudinal study in the United Kingdom. ${ }^{28}$ So, further studies are needed to predict anxiety and depression diagnosis among patients with multiple visits with unexplained medical symptoms.

Painful muscles and back pain are the most common somatic symptoms in our study and were significantly more frequent among clients with SDD. Similarly, back pain and tiredness were more frequently related to this condition in Turkish migrants living in Germany ${ }^{30}$. Stomach pain and painful leg and arm joints were more frequent associations among the Iranian population. ${ }^{6}$ Different symptoms may be related to SSD in different groups and cultures. Thus, PHC physicians should have a high index of suspicion to predict SSD, especially among patients with these complaints, if no underlying medical diagnosis could be reached. Moreover, a valid screening tool should be available in a PHC setting to be used by physicians in high-risk patients.

The study has many strong points, including novelty, using a standard questionnaire that has been designed specially to be used in PHC settings and the large sample size that could reduce sampling bias. However, some limitations should be taken into consideration as the study was based on self-reported data, which makes the reliability of the findings questionable. In order to ensure the reliability of participants' responses, the interviews were conducted in a place that guaranteed their privacy and was administered by trained family physicians who used a standardized procedure in data collection. Secondly, given the large sample size for this study to determine the prevalence, it is likely that the sample was not powerful enough to identify substantial differences with individual determinants. Lastly, being a cross-sectional study, not longitudinal, precludes any causal association between SSD and its risk factors.

In conclusion, SSD is prevalent in PHC settings, challenging physicians for possible diagnosis, resulting in increased utilization of healthcare resources, and increased cost. Patients with multiple visits per month could have SSD and move undiagnosed for an extended period. A high index of suspicion, improving physicians' skills in mental health disease diagnosis, and a validated screening tool are 
recommended at PHC to decrease the burden of this disease on patients, physicians, or the healthcare system.

\section{List Of Abbreviations}

\begin{tabular}{ll} 
AUC & Area Under The Curve \\
\hline $\mathrm{Cl}$ & Confidence Intervals \\
\hline DSM-V & Diagnostic Statistical Manual $5^{\text {th }}$ edition \\
\hline 4DSQ & four-Dimensional Symptom Questionnaire \\
\hline OR & Odds Ratios \\
\hline PHC & Primary Health Care \\
\hline ROC & Receiver Operating Characteristic \\
\hline SAD & Somatization-Anxiety-Depression \\
\hline SSD & Somatic symptom disorder
\end{tabular}

\section{Declarations}

\section{Ethics approval and consent to participate:}

All subjects involved in the study were invited to participate on a voluntary basis after the study purpose, risk, and advantage of participation were clarified. Informed consent was obtained from all participants. Interviews were carried out in accordance with the Code of Ethics of the World Medical Association (Declaration of Helsinki). Approval of the An-Najah National University institutional review board was obtained. Participants' privacy and confidentiality were ensured.

\section{Consent for publication:}

"Not applicable."

\section{Availability of data and materials:}

The dataset supporting the conclusions of this article is included within the article and its additional file.

\section{Competing interests:}

"The authors declare that they have no competing interests" in this section. 


\section{Funding:}

No funding received for this study from any source.

\section{Authors' contributions:}

ZN and MA Participated in conceiving and study design, supervised data collection, data analysis, manuscript writing. ZN, MA, BM, LQ and RA performed the material preparation, data collection and analysis. All authors interpreted the results. The first draft of the manuscript was written by BM and all authors commented on previous versions of the manuscript. All authors read and approved the final manuscript.

\section{Acknowledgments:}

Researchers are grateful to An-Najah National University for their support and to Palestinian Ministry of Health for facilitation our access to primary health care centers. We gratefully thank the research participants.

\section{References}

1. Kroenke K. Somatization in Primary Care An Inclusive Approach to the Symptomatic Patient. APS J. 1993;2(3):150-153.

2. Association AP. Diagnostic and Statistical Manual of Mental Disorders: DSM-5.; 2013.

3. Al Busaidi ZQ. The Concept of Somatisation: A Cross-cultural perspective. Sultan Qaboos Univ Med J. 2010;10(2):180-186.

4. Rosendal M, Blankenstein N, Morriss R, Fink P. Enhanced care by generalists for functional somatic symptoms and disorders in primary care Review information Contact person. 2013;(October 2018). doi:10.1002/14651858.CD008142.pub2

5. Alkhadhari S, Alsabbrri A, Mohammad I, Atwan A, Alqudaihi F, Zahid M. Prevalence of psychiatric morbidity in the primary health clinic attendees in Kuwait. J Affect Disord. 2016;195. doi:10.1016/j.jad.2016.01.037

6. Garrusi B, Danaei M, Aboosaeidi R. The prevalence and predictive factors of somatization and its relationship with anxiety and depression in Iranian population. J Prev Med Hyg. 2019;60(4):E400E406. doi:10.15167/2421-4248/jpmh2019.60.4.1006

7. Löwe B, Spitzer RL, Williams JBWW, Mussell M, Schellberg D, Kroenke K. Depression, anxiety and somatization in primary care: syndrome overlap and functional impairment. Gen Hosp Psychiatry. 2008;30(3):191-199. doi:10.1016/j.genhosppsych.2008.01.001 
8. Bekhuis E, Boschloo L, Rosmalen JGM, Schoevers RA. Differential associations of specific depressive and anxiety disorders with somatic symptoms. J Psychosom Res. 2015;78(2):116-122. doi:https://doi.org/10.1016/j.jpsychores.2014.11.007

9. Kohlmann S, Gierk B, Hilbert A, Brähler E, Löwe B. The overlap of somatic, anxious and depressive syndromes: A population-based analysis. J Psychosom Res. 2016;90:51-56. doi:https://doi.org/10.1016/j.jpsychores.2016.09.004

10. Hanel G, Henningsen P, Herzog W, et al. Depression, anxiety, and somatoform disorders: Vague or distinct categories in primary care? Results from a large cross-sectional study. J Psychosom Res. 2009;67:189-197. doi:10.1016/j.jpsychores.2009.04.013

11. Bohman H, Jonsson U, Von Knorring A-L, Von Knorring L, Päären A, Olsson G. Somatic symptoms as a marker for severity in adolescent depression. Acta Paediatr. 2010;99(11):1724-1730. doi:10.1111/j.1651-2227.2010.01906.x

12. Bener A, Al-Kazaz M, Ftouni D, Al-Harthy M, Dafeeah EE. Diagnostic overlap of depressive, anxiety, stress and somatoform disorders in primary care. Asia Pac Psychiatry. 2013;5(1):E29-38. doi:10.1111/j.1758-5872.2012.00215.x

13. Terluin B, Smits N, Miedema B. The English version of the four-dimensional symptom questionnaire (4DSQ) measures the same as the original Dutch questionnaire: a validation study. Eur J Gen Pract. 2014;20(4):320-326. doi:10.3109/13814788.2014.905826

14. Terluin B, van Marwijk HWJ, Adèr HJ, et al. The Four-Dimensional Symptom Questionnaire (4DSQ): a validation study of a multidimensional self-report questionnaire to assess distress, depression, anxiety and somatization. BMC Psychiatry. 2006;6(1):34. doi:10.1186/1471-244X-6-34

15. Leutgeb R, Berger S, Szecsenyi J, Laux G. Patients with somatoform disorders: More frequent attendance and higher utilization in primary out-of-hours care? PLoS One. 2018;13(8). doi:10.1371/journal.pone.0202546

16. Haller $\mathrm{H}$, Cramer $\mathrm{H}$, Lauche $\mathrm{R}$, Dobos $\mathrm{G}$. Somatoform disorders and medically unexplained symptoms in primary care. Dtsch Arztebl Int. 2015;112(16):279-287. doi:10.3238/arztebl.2015.0279

17. Alkhadhari S, Alsabrrie AO, Ohaeri JU, Varghese R, Zahid MA, Mulsant BH. Mental and physical comorbidity in an Arab primary health care setting. BMC Psychiatry. 2018;18(1):313. doi:10.1186/s12888-018-1903-8

18. van Eck van der Sluijs JF, Ten Have M, Rijnders CA, van Marwijk HW, de Graaf R, van der FeltzCornelis $\mathrm{CM}$. Mental health care use in medically unexplained and explained physical symptoms: findings from a general population study. Neuropsychiatr Dis Treat. 2016;12:2063-2072. doi:10.2147/NDT.S109504

19. de Waal MWM, Arnold IA, Eekhof JAH, van Hemert AM. Somatoform disorders in general practice: prevalence, functional impairment and comorbidity with anxiety and depressive disorders. $\mathrm{Br} \mathrm{J}$ Psychiatry. 2004;184:470-476. doi:10.1192/bjp.184.6.470

20. Toft T, Fink P, Oernboel E, Christensen K, Frostholm L, Olesen F. Mental disorders in primary care: prevalence and co-morbidity among disorders. results from the functional illness in primary care 
(FIP) study. Psychol Med. 2005;35(8):1175-1184. doi:10.1017/s0033291705004459

21. Kleinstäuber M, Witthöft M, Hiller W. Efficacy of short-term psychotherapy for multiple medically unexplained physical symptoms: A meta-analysis. Clin Psychol Rev. 2011;31(1):146-160. doi:https://doi.org/10.1016/j.cpr.2010.09.001

22. Barsky AJ, Peekna HM, Borus JF. Somatic symptom reporting in women and men. J Gen Intern Med. 2001;16(4):266-275. doi:10.1046/j.1525-1497.2001.00229.x

23. Sartorius N, Holt R, Maj M, eds. Comorbidity of Mental and Physical Disorders. 179th ed. Karger AG; 2015.

24. van Eck van der Sluijs JF, ten Have M, de Graaf R, Rijnders CAT, van Marwijk HWJ, van der FeltzCornelis CM. Predictors of Persistent Medically Unexplained Physical Symptoms: Findings From a General Population Study. Front Psychiatry. 2018;9:613. doi:10.3389/fpsyt.2018.00613

25. Babu AR, Sreedevi A, John A, Krishnapillai V. Prevalence and Determinants of Somatization and Anxiety among Adult Women in an Urban Population in Kerala. Indian J Community Med. 2019;44(Suppl 1):S66-S69. doi:10.4103/ijcm.IJCM_55_19

26. Egede LE. Major depression in individuals with chronic medical disorders: prevalence, correlates and association with health resource utilization, lost productivity and functional disability. Gen Hosp Psychiatry. 2007;29(5):409-416. doi:10.1016/j.genhosppsych.2007.06.002

27. Scott KM, Lim C, Al-Hamzawi A, et al. Association of Mental Disorders With Subsequent Chronic Physical Conditions: World Mental Health Surveys From 17 Countries. JAMA psychiatry. 2016;73(2):150-158. doi:10.1001/jamapsychiatry.2015.2688

28. van Boven $\mathrm{K}$, Lucassen $\mathrm{P}$, van Ravesteijn $\mathrm{H}$, et al. Do unexplained symptoms predict anxiety or depression? Ten-year data from a practice-based research network. Br J Gen Pract. 2011;61(587):e316-e325. doi:10.3399/bjgp11X577981

29. Haug TT, Mykletun A, Dahl AA. The association between anxiety, depression, and somatic symptoms in a large population: the HUNT-II study. Psychosom Med. 2004;66(6):845-851.

doi:10.1097/01.psy.0000145823.85658.0c

30. Morawa E, Dragano N, Jöckel K-H, Moebus S, Brand T, Erim Y. Somatization among persons with Turkish origin: Results of the pretest of the German National Cohort Study. J Psychosom Res. 2017;96:1-9. doi:10.1016/j.jpsychores.2017.02.014

\section{Figures}




\section{ROC Curve}

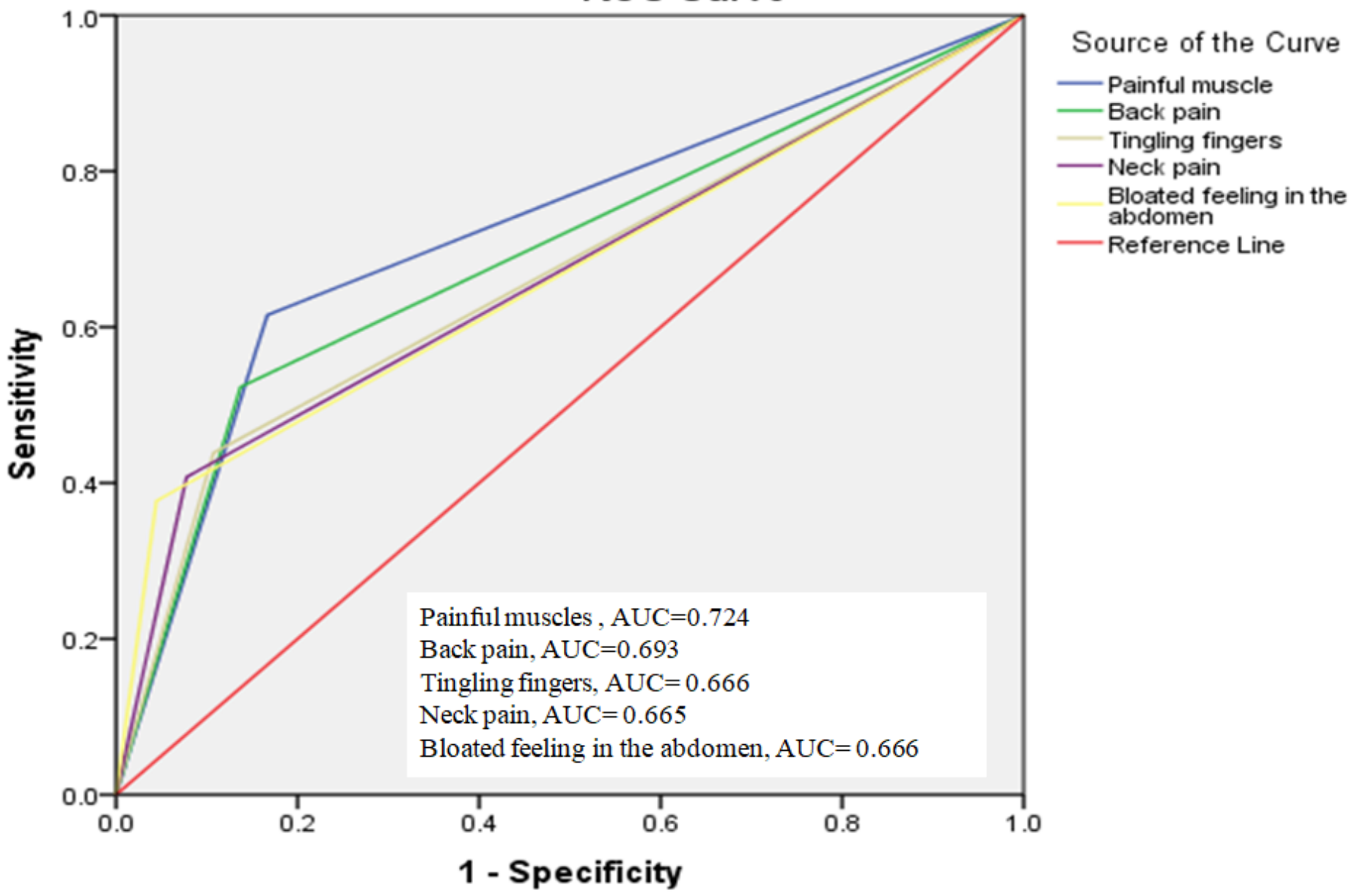

\section{Figure 1}

Receiver operating characteristic curve of physical complaints (painful muscle, back pain, tingling fingers, neck pain, and feeling in the abdomen) for the Somatic symptom disorder scores. The area under the curve (AUC) ranged between 0.66 and 0.72 .

\section{Supplementary Files}

This is a list of supplementary files associated with this preprint. Click to download.

- Rowdata.xlsx 